\title{
“A CASA DE VIDRO”: O IMPULSO DISTÓPICO NAS LINHAS DURAS DE IVAN
}

ÂNGELO

Thaíse Gomes Lira ${ }^{1}$

Luciane Alves Santos ${ }^{2}$

RESUMO: O pensamento utópico não surgiu com Utopia (1516), de Morus, mas a ficção ainda sente a sua influência: o pensamento utopista e a especulação sobre um mundo melhor estimularam a criação de obras que focam a desordem e desarmonia. Na ficção utópica surgem as condições para a Distopia, e aqui analisamos "A casa de vidro" (Ivan Ângelo), um dos textos distópicos originalmente escritos em português. Distopias proporcionam análises social e política, têm aspectos peculiares, surgiram no século XIX e se firmaram no século XX. São marcadas pelo totalitarismo, centralização de poder, plano u/distópico, repressão do indivíduo, controle pela violência, questionamento do status quo, alienação popular; alta tecnologia, liberdade vigiada, (não) heróis banidos. Este fundamenta-se em Arendt (1979), Figueiredo (2009), Foucault (1987), Kothe (1985), Todorov (2013) e Tomachevski (2013). Esperamos que esta pesquisa contribua para novos estudos sobre as Distopias brasileiras e seu poder de análise da sociedade.

Palavras-chave: A casa de vidro; Ivan Ângelo; Autoritarismo; Distopia.

ABSTRACT: Utopia thought did not arise with Utopia (1516), by Morus, but fiction still feels its influence: the utopian thought and speculation about a better world have stimulated the creation of works that focus on disorder and disharmony. In Utopian fiction the conditions for Dystopia arise, and here we analyze "A Casa de Vidro" ("The House of Glass", by Ivan Ângelo), one of the dystopic texts originally written in Portuguese. Dystopias provide social and political analysis; they have peculiar aspects and they emerged in the nineteenth century and strengthened in the twentieth century. They are marked by totalitarianism, centralization of power, $\mathrm{u} /$ dystopic plan, repression of people, control by violence, questioning of the status quo, popular alienation; high tech, a watched freedom, anti heroes banned. This work is based on Arendt (1979), Figueiredo (2009), Foucault (1987), Kothe (1985), Todorov (2013) and Tomachevski (2013). We hope that this research can contribute to new studies on Brazilian Dystopias and their power for analysing society.

Keywords: The glass house; Ivan Ângelo; Authoritarianism; Dystopia.

CONSIDERAÇÕES INICIAIS

Não nos cabe julgar a História, mas dela retirar lições, a partir dela refletir.

(Ivan Ângelo)

"Utopia” foi um termo cunhado por Thomas More, em 1516, para intitular sua magnus opum, e também a ilha harmônica encontrada por seu amigo navegador Rafael Hitlodeu. O pensamento

\footnotetext{
${ }^{1}$ Mestranda no Programa de Pós-Graduação em Letras, da UFPB, na área Literatura, Cultura e Tradução. E-mail: thaiserevisao@gmail.com.

${ }^{2}$ Professora da Universidade Federal da Paraíba, Campus IV, vinculada ao programa de Mestrado Profissional em Letras/ CAPES e ao Programa de Pós-graduação em Letras (PPGL). E-mail: luciane.ufpb@gmail.com.
} 
utópico, porém, pode ser rastreado até $A$ República, de Platão (século IV a. C.) e O príncipe, de Maquiavel (1513). A construção do pensamento utópico, da especulação sobre um mundo melhor, também estimulou a criação de obras que focam a desordem e desarmonia, na contramão dos ideais apresentados por More. É no terreno da ficção utópica que surgem as condições para a narrativa distópica - a abordagem de um plano utópico que falhou.

"A casa de vidro", de Ivan Ângelo, é um dos poucos textos distópicos originalmente escritos em língua portuguesa. A ficção distópica é uma ferramenta contumaz de análise social e política, e faz parte do macrogênero Insólito ficcional, mas seu potencial genológico e sua caracterização relativamente independente, construída ao longo do século XIX, com Mary Shelley e H. G. Wells, e consolidada no século XX, com Yevgeny Zamiátin, Aldous Huxley e George Orwell, permite a aproximação entre essas obras - outrora classificadas como de ficção Científica ou fantasia - e a Literatura distópica.

A diegese distópica admite uma caracterização específica, com a maturação experimentada no decorrer de dois séculos, de forma que comprovou sua relativa independência da Ficção Científica, uma das suas inspirações mais fortes. É mais do que uma vertente ou subgênero: a Distopia já construiu seu espaço e adquiriu forma própria, o que fundamentamos no proposto por Tomachevski (2013, p. 350-351), que defendia a possibilidade de evolução do gênero literário.

O formalista russo percebia os gêneros como classes especiais na arte, ou a reunião de procedimentos, combinados em sistemas, aplicados em obras distintas. Ele acreditava, ainda, que os gêneros não eram estanques, posto que vivem e desenvolvem-se; partia do princípio de que algumas obras compunham um gênero específico em dado momento do tempo e, posteriormente, verificavamse obras que podiam assemelhar-se ou não com aquele grupo: "O gênero", afirma Tomachevski (2013, p. 352), “enriquece-se de obras novas que se vinculam às obras já existentes do gênero dado. A causa que promoveu um gênero pode não mais agir; os traços fundamentais do gênero podem mudar lentamente, mas o gênero continua a viver enquanto espécie (...)”. É a favor da evolução e, por vezes das revoluções dos gêneros que o formalista se posiciona.

A reflexão de Tomachevski permite pensar os gêneros literários não como sistemas herméticos e acabados, mas como procedimentos da Literatura que têm potencial de mutação e de geração de novos gêneros, a partir do enriquecimento que os primeiros gêneros e a Literatura Clássica lhes legaram. Os novos grupos genológicos frutificam e são nutridos a partir da criação e publicação de novas obras, que somam à sua "espécie" não apenas em quantidade, mas em releituras estruturais e 
no questionamento sobre o que pode ser melhorado em uma determinada sociedade - o que é perceptível nas distopias canônicas do século XX.

As narrativas distópicas permitem ao leitor e aos seus protagonistas abrirem as janelas da investigação e do questionamento de mazelas sociais, bem como serem confrontados com as consequências de um plano utópico falho: uma situação ideal foi engendrada, porém seus resultados não foram benéficos a todos os envolvidos, então o leitor e também o personagem submetido às forças opressoras indagará: Para quem aquele plano era, de fato, ideal?

Este artigo analisa o conto "A casa de vidro", publicado em 1979, no contexto da Ditadura militar brasileira. Em seu texto, Ivan Ângelo reúne todos os traços levantados por Figueiredo (2009) e os elementos que identificamos na construção da narrativa distópica contemporânea. A relevância da análise de obras desse gênero reside no fato de estas instigarem no leitor um alerta às possibilidades de transformação do mundo como o conhecemos, em particular quando essa mudança é disfarçada sob um véu de boas intenções e a pecha de uma grande revolução global, mas esconde objetivos escusos, mesquinhos.

Não se trata de uma mudança de conotação fantástica, como delineia Todorov (2013, p. 148), pela inserção de um evento estranho à nossa realidade e que gera ambiguidade, mas da representação de uma sociedade modificada segundo um núcleo de Poder que engendrou um plano utópico voltado a seus próprios interesses, e com prejuízo da população em geral. Figueiredo (2009, p. 33) aponta que a utopia engendra a distopia, e trata o universo distópico como "um mundo onde os sujeitos são submetidos a um poder central, totalitário e têm suas liberdades individuais continuamente cerceadas". A grande massa, porém, afirma Figueiredo, aparenta organização e felicidade, sem qualquer insatisfação.

O artigo está fundamentado nas contribuições de Arendt (1979) sobre o totalitarismo; Figueiredo (2009) acerca das distopias; Foucault (1987) e sua ideia de vigilância e punição; Kothe (1985) sobre o anti-herói; Todorov (2013) e seus apontamentos sobre gênero e, por fim, Tomachevski (2013) e seus estudos sobre a evolução dos gêneros.

Totalitarismo e centralização de poder, crítica social, plano u/distópico e repressão da liberdade individual; o controle pela ameaça e pelo medo versus o questionamento do status quo, em paralelo à alienação de um povo que não tem vez ou voz; uma tecnologia de ponta, o pequeno homem vigiado, os heróis (não heróis) que se opõem ao sistema são banidos ou eliminados; morte, dor e 
liberdade são vistas com apatia e passividade. São estes os traços identificados no conto de Ângelo (1979) e que desenvolveremos a seguir.

\section{NAS LINHAS E ENTRELINHAS DE ÂNGELO, A DISTOPIA REINANTE EM SOLO TUPINIQUIM}

O conto de Ivan Ângelo ocorre em um tempo e espaço indefinidos, apesar dos indícios de sua ambientação nos nossos tempos. Seu protagonista é o Experimentador: cientificista, ele cria e propõe às autoridades locais um experimento repressivo com presidiários: uma casa de vidro, na qual os internos estariam completamente expostos à população passante, bem como a administração, o centro de comunicações, refletindo uma suposta transparência. Apesar do choque inicial após a construção da casa, a prisão, posteriormente, se tornou parte do cotidiano daquele povo que passava sem mais percebê-la ou questionar os absurdos que lá ocorriam.

"A Casa de Vidro" nos insere em uma atmosfera distópica a partir de sua abertura: "Houve protestos. Proibiram os protestos" (ÂNGELO, 2006, p. 161). Aqui registramos um primeiro aspecto: a repressão da liberdade individual, o direito de reação duramente coibido, em favor do silêncio geral para o prosseguimento de um plano previamente elaborado como se fosse benéfico a toda aquela sociedade: um projeto que foi do utópico ao distópico porque seus interesses eram voltados ao núcleo de poder, em vez da grande massa popular. E a repressão atinge todos os núcleos submissos às autoridades.

A crueldade sem ressalvas e uma insistente vigilância do "pequeno" homem, do oprimido, também está presente nas narrativas distópicas. Ângelo (2006, p. 163), apresenta o primeiro preso, "um homem preto, perplexo, e roupas simples, olhos inquietos", e menciona que "olhos discretos observaram o dia do preso". Percebemos, a partir do cenário de um dos internos em observação naquele recorte temporal, que aquela é uma prisão pretensamente escancarada, disfarçada de transparências, porém com cerne nas aparências; uma "liberdade vigiada" (FOUCAULT, 1987, p. 22), um cenário cruel.

A Casa revela a crueldade de limitar os direitos de ir e vir dos indivíduos, considerados “inimigos do Estado" por acusações que não são apresentadas, e que podem ir de roubo ou assassinato a um posicionamento rebelde contra o governo -ainda, expondo-se tal situação em praça pública. Mas 
a crueldade não se restringe às autoridades: caminha de mãos dadas com o cidadão que destruía relógios e "matava bicho apenas para ver como eram por dentro" (ÂNGELO, 2006, p. 172), e também com quem passou a virar rosto para o que ocorria na casa de vidro, por medo de ser preso ou morto.

A população se cala e aconselha o silêncio aos demais, abre mão de sua voz e sua vez, deixa de olhar e tenta apenas seguir seu caminho, porque “(...) eles podem não gostar” (ÂNGELO, 2006, p. 164). O pronome "eles" é frequentemente utilizado no conto como forma de referência às autoridades, que são os Chefes e todos os representantes do núcleo de Poder; dessa forma, os cidadãos se sentem mais livres para criticar um sistema que lhes desagrada sem referências diretas, ou seja, priorizando a sua própria segurança.

Outro aspecto relevante para analisar a Distopia em Ângelo é a opressão de algumas classes sobre outras. Em A máquina do tempo (1895), de H. G. Wells, os Morlocks são seres confinados ao subsolo, durante o dia, mas que oferecem opressão à noite sobre os Elois - os quais precisam permanecer em locais seguros, se quiserem viver; em 1984 (1949), de George Orwell, os proletas, que formam a maior parte da população, são constantemente vigiados pelo Grande Irmão e oprimidos pelo sistema, o Big Brother e o Partido dominante. Em "A casa de vidro", os oprimidos estão divididos em dois grupos: os presos e o público externo à prisão, composto por familiares, amigos e conhecidos dos internos. Os presidiários não são ouvidos, tampouco se registra a sua voz de qualquer forma: aqueles que se expressam, fazem-no por tímidos sinais ou desenhos no vidro, tão efêmeros quanto o tempo de um suspiro quente na fria superfície vítrea.

Existem dois grandes grupos no conto: os opressores e os oprimidos. Estes se subdividem entre presos internos e externos à prisão (familiares, amigos e passantes); aqueles reúnem as principais autoridades e seus associados. Os Chefes representam, na narrativa, o centro de poder e da tomada de decisões; a eles, é apresentada a proposta do experimento da Casa de Vidro, que aprovam e cuja construção e efetivação acompanham. O Experimentador é o cientista social, quem conduz o Experimento, e quer a vitória contra o Ódio em até três anos. São estes os "criadores da prisão vitrina, o shopping center da humilhação, a sua mais recente e quem nos dera última agressão à Sociedade" (ÃNGELO, 2006, p. 169). Aliados aos Chefes e ao Experimentador, há o Arquiteto, que desenvolve o projeto da Casa e a edifica naquela cidade desconhecida; por fim, há o Setor de Informações, que libera e proíbe na imprensa o que é desejado e liberado pelo Poder.

Os internos não são os reais vigiados, afinal, o experimento desenvolvido e conduzido pelo Experimentador oferece uma visão mais abrangente das pessoas que estão fora da Casa de Vidro do 
que dos presos; são escutas telefônicas, gravações que se sucedem, pessoas que têm sua privacidade escancarada a cada pausa e (Ruído). Estas também têm sua voz silenciada e aceitam-no, pois é preferível perder sua voz e sua vez a arriscar enfurecer os guardas e o Poder Central, afinal tudo aquilo é coisa deles e é "melhor não se meter" (ÂNGELO, 2006, p. 162).

Em dado momento, porém, a prisão de vidro tem sua dureza suavizada pela suposta bonança que aquela "cristalinidade" proporciona. Partindo do modo de pensar "tudo o que vejo é melhor do que aquilo que eu imagino", isto torna-se claro no posicionamento de alguns personagens, ao declararem que ali, de forma tão "aberta", existe uma situação mais acalentadora do que as antigas prisões fechadas, quando não se tinha certeza do que sucedia aos internos, pelo fato de estarem trancafiados em celas de cimento escuras, isolados por completo da sociedade:

Eu penso naquela nossa angústia, quando os muros eram fechados, quando a gente mal podia imaginar o que acontecia lá dentro. O não saber, não ver um filho, um irmão, um pai, dava uma angústia tão grande que as pessoas quase ficavam loucas, correndo atrás de advogados, juízes, jornais. Hoje é tudo tão claro. (ÂNGELO, 2006, p. 187)

No entanto, a partir do momento em que os presos visíveis são levados pelos guardas para seus misteriosos e definitivos destinos, para jamais serem vistos novamente, o leitor e os passantes da casa de vidro percebem que a Verdade ali proposta não é assim tão escancarada.

Após sofrer os desmandos de um governo ditatorial por vinte anos, o Brasil possui cicatrizes históricas que inspiraram a distopia na narrativa de Ângelo em um aspecto primordial: o totalitarismo. A realidade distópica se banha em uma atmosfera de controle pela violência, ameaça ou medo: os guardas ou sentinelas permanecem armados o tempo inteiro; em dado momento, uma figura entra na cela, fala expansivamente e com gestos de intimidação, de forma que o interno naquele recorte se encolhe mais e mais; as pessoas, arrebanhadas em uma grande massa dominada, vivenciam o seu isolamento enquanto indivíduos, cercados pelas amarras da tirania instaurada, o que nos remete a Arendt (1979), quando afirma que:

O governo totalitário, como todas as tiranias, certamente não poderia existir sem destruir a esfera da vida pública, isto é, sem destruir, através do isolamento dos homens, as suas capacidades políticas. Mas o domínio totalitário como forma de governo é novo no sentido de que não se contenta com esse isolamento, e destrói também a vida privada. Baseia-se na solidão, na experiência de não se pertencer ao mundo, que é uma das mais radicais e desesperadas experiências que o homem pode ter. (ARENDT, 1979, p. 527) 
Arendt defende uma aura nova ao redor do totalitarismo, que se centra nos aspectos de ideologia e terror, e que se afasta da política ocidental, como foi estabelecida; para a autora, não há conexão com o despotismo ou a tirania, visto que o governo totalitário não decai na ilegalidade de um cerne tirânico, por que se identifica com a própria lei humana (ARENDT, 1979, p. 515); um Domínio se faz presente, preza pelo núcleo de Poder em uma sociedade, que burocratiza, institucionaliza a violência, e ainda possui as vantagens de ser considerado legalizado:

A esta altura, torna-se clara a diferença fundamental entre o conceito totalitário de lei e de todos os outros conceitos. A política totalitária não substitui um conjunto de leis por outro, não estabelece o seu próprio consensus iuris, não cria, através de uma revolução, uma nova forma de legalidade. O seu desafio a todas as leis positivas, inclusive às que ela mesma formula, implica a crença de que pode dispensar qualquer consensus iuris e ainda assim não resvalar para o estado tirânico da ilegalidade, da arbitrariedade e do medo. Pode dispensar o consensus iuris porque promete libertar o cumprimento da lei de todo ato ou desejo humano; e promete a justiça na terra porque afirma tornar a humanidade a encarnação da lei. (ARENDT, 1979, p. 514-515)

É deste fundamento que se alimentam os Chefes e o projeto do Experimentador: considerados autoridades responsáveis, instauram e perpetuam um sistema de poder que foi criado dentro de parâmetros legais - e que, mesmo não sendo completamente lícito, aos nossos olhos, tornou-se aceitável e respeitável perante uma sociedade quieta, apática e não questionadora, em sua maioria. Quem questionaria o sistema, quem ainda se veria no lugar do Outro?

A presença de empatia e alteridade é discutível nas distopias: seus personagens raramente apresentam estas características. Na diegese distópica, é frequente que o cidadão comum se sinta ameaçado o suficiente para se submeter ao poder vigente e abandonar qualquer desejo ou chance de se colocar no lugar do outro. Porém, em "A casa de vidro", o próprio material físico leva a uma reflexão interna e externa sobre a situação instaurada: "Certas horas da manhã e da tarde, dependendo da posição do sol, o vidro reflete um pouco, sem deixar de ser transparente. E então a gente vê, lá dentro, a gente mesmo, junto com o outros" (ÂNGELO, 2006, p. 181).

A construção da Casa ultrapassou o isolamento e solidão: tamanha era a claridade e nitidez dos reflexos no "super vidro", que as pessoas podiam enxergar-se lá dentro. Em alguns momentos, viam-se como quem apanhava; em outros, como quem batia. Mas isto não instigou a simpatia de uma população apática, que, uma vez reprimida pela força, não ousou mais esboçar qualquer reação rebelde. 
Os guardas, apesar de a brilhante tecnologia do vidro ser à prova de balas, mantinham sua posição com metralhadoras em punho, à espera do próximo rebelado, o que nos remete a mais um aspecto importante da literatura distópica, que é a presença de tecnologias avançadas demais para aquela época ou lugar.

Um dos poucos personagens nomeados no conto, Nelson explica o quão é diferenciada e estranha em sua cidade aquela nova composição de vidro, quando questionado sobre o material de que era feita: o tipo mais comum provém de uma fusão de quartzo, areia branca e lavada, com carbonato de sódio e cal; a nova fórmula, porém, era desconhecida, transparente ao extremo, devia ser feita "na base de chumbo" (ÂNGELO, 2006, p. 186), pois o vidro era duro e resistente a calor e impactos e, certamente, aquela fórmula não era coisa daquele lugar. Nelson registra a sua individualidade e é um dos poucos que percebemos sendo levados a pensar sobre o processo de fabricação do material da casa. Este permanece em mistério, visto que ninguém conhece a composição exata do material extremamente avançado para aquela sociedade, ou de que forma ele é produzido. O narrador apresenta o vidro como algo criado após o marco temporal do Grande Avanço. Antes deste, o material não tinha a qualidade de então, quando não se pode ver sequer a transparência: os passantes e presos sabem que existe vidro ali porque o vento não passa por aquela barreira invisível.

Não apenas os vidros são aparatos tecnológicos que merecem nota. Boa parte do conto se desenvolve em diálogos de gravadores, de escutas telefônicas implantadas de modo enigmático - não sabemos como foram instaladas em casas, nas ruas e nos locais mais inacreditáveis sem a percepção do povo, porém, estão registrando cada detalhe das vidas vigiadas. Em dado momento, os cidadãos se apavoram porque dizem que "eles estão fotografando as pessoas" (ÂNGELO, 2006, p. 162), grifo nosso, e reiteramos o uso do pronome como forma de isenção de culpa perante o governo regente. O Experimentador representa a ciência e é responsável pelo experimento; apresenta orgulhoso os resultados de um mês de gravações. O que para nós soa como diálogos cotidianos, para o cientista denota a vigilância ininterrupta de pessoas inseridas em seu experimento social forçado. A categoria Personagem é uma das mais relevantes na distopia, em particular neste conto, no qual Ivan Ângelo demonstrou o cuidado de reduzir a nomeação de personagens e de ampliar a representação de grupos sociais.

Mais um aspecto presente em distopias desde o século XIX é a massificação ou os agrupamentos sociais. Assim como H. G. Wells, em A Máquina do Tempo (1895), e Zamyatin, em Nós (1924), os indivíduos em “A casa de vidro" (1979) raramente apresentam uma existência 
singularizada ou a mesma relevância que os grupos sociais representados na obra: o Experimentador, os Chefes, o Arquiteto, os presos, as famílias dos presos. A generalização prevalece sobre a especificação e denota as proporções globais daquele plano supostamente utópico, de acabar com o que denominavam “o Ódio”. São Personagens Tipos, que favorecem uma linha de pensamento na qual tais indivíduos não representam vozes singulares, mas grandes grupos, os quais incorporam com suas vestes, sua cor, sua história.

O Experimentador, os Chefes e demais figuras de poder protagonizam um sistema de encarceramento "transparente", que visa a escancarar a ausência da liberdade individual, e a pregar aquilo como uma tática de transparência das autoridades. O plano proposto como um grande experimento social não é completamente aceito por todos, e existe uma reação não tão imediata: pessoas se explodem, cortam e esfolam em protesto à prisão de vidro, de forma a demonstrar sua insatisfação com aquele projeto. Uma reação sempre coibida pela força: "Toda insubordinação deve ser punida! (...) tudo que não produz, que leva à dúvida, à frustração e à insubordinação deve ser capado!"' (ÂNGELO, 1979, p. 177). Este trecho expressa dois aspectos primordiais da narrativa distópica: o sistema de governo regente que usa da ameaça, medo e força para reprimir a população envolvida em seu plano u/distópico; e a punição daqueles que se rebelam contra o sistema: são banidos, exilados, punidos, capados.

É “a verdade” que desejavam, quando veio a implantação do grande plano. Mas uma verdade escolhida a dedo pelos regentes: um quadro pintado com as cores certas. No conto, o autor critica a censura que se firmou durante as duas décadas de vigência da Ditadura no Brasil, em particular a partir da década de 1970: às manchetes e matérias manipuladas, aos jornais que eram submetidos a censores de informação, à necessidade que brotou, na imprensa alternativa, de criticar a perseguição política, os inúmeros desaparecimentos, até hoje não resolvidos, e a tortura de presos políticos e opositores do governo. O cenário é apocalíptico e pessimista, como se verificam nas distopias oitocentistas, a exemplo de $O$ último homem (1826), de Mary Shelley: porém, no conto de Ivan Ângelo, não há dimensões mundiais, trata-se do apocalipse pessoal, da coibição de direitos e de gozo dos próprios direitos humanos.

Mais dois aspectos relevantes na análise distópica são: a projeção em um tempo futuro e a centralização do espaço da narrativa. O conto de Ângelo não tem um marco temporal claro mas sabemos que o autor o redigiu em meio à Ditadura Militar. Por outro lado, ele nos apresenta a expressão “antes do Grande Avanço” (ÂNGELO, 2006, p. 161), para se referir a algum fato que permaneceu 
omitido no texto, mas que representou um ponto de virada e de progresso naquela sociedade: claramente, o texto nos insere na fase "após o Grande Avanço". Partindo do exposto, deduzimos que, embora a narrativa se desenvolva em nosso passado real, a sua ambientação é em um futuro indeterminado, definido pelas marcas do progresso instaurado.

O autor ainda utiliza o recurso do fluxo de consciência (ÂNGELO, 2006, p. 177-178) como forma de propiciar ao leitor o entendimento de tempo em progresso, com as ações sucedendo rápida e ininterruptamente, enquanto aquilo é registrado de forma breve. A despeito de sua efemeridade, porém, os fatos em sequência possuem tamanha importância, como os poemas intercalados na narrativa, que, em vez de serem resumidos a uma frase de tempo transcorrido, precisam criar o elemento imagético, para que compreendamos exatamente quais pessoas foram afetadas por aquela última decisão dos Chefes, e quão rápido aquelas consequências alcançaram os cidadãos locais.

O espaço da narrativa, por sua vez, se restringe à Casa de Vidro, ao seu interior e também seu entorno: nos presos, nas pessoas na rua, na Administração e no Setor de comunicações. Nos primeiros parágrafos do conto, Ângelo (2006, p. 161) menciona que a Casa fora erguida sobre um prédio de alvenaria, onde outrora funcionava a central de polícia. Finalmente, um dos aspectos mais fortes da narrativa distópica é identificado na presença de um embate entre o questionamento do status quo e da alienação pública. Uma das escolhas lexicais dignas de nota no conto traz uma ordenação de verbos que nos apresenta o tom daquela população em poucas palavras (ÂNGELO, 2006, p. 161-162): "(Como? Uma vitrina aqui? - passavam e pensavam os de fora) / Logo substituíam os muros laterais; / (Nossa! Vai-se ver tudo! - pensavam, passavam).

O excerto apresenta dois momentos na atitude dos cidadãos vigiados: o questionamento inicial e a passividade final. Em um primeiro instante, há certa admiração pela construção de uma vitrina ali, no meio da cidade. O autor utiliza os verbos na seguinte ordem: Passavam e pensavam os de fora; supomos que após passarem pelo local, os indivíduos - que, sem nomes, representam a massa - foram levados a questionar sobre o papel daquela grande vitrine na cidade. Essa surpresa se estende durante parte da narrativa, o que corresponde ao tempo em que a dúvida se transformou em revolta e em ação, por parte dos transeuntes que se rebelaram contra a casa. Em seguida, os verbos surgem em ordem oposta. "Nossa! Vai-se ver tudo! - pensavam. Passavam”. Aqui, o autor demonstrou que, a despeito da admiração, da revolta e da ação contra o sistema, os elementos estavam fadados a cair na passividade, em um completo alheamento ao que se desenvolve naquela Casa. O que antes era horrível, tornou-se comum, atração turística, fato corriqueiro e de passagem, "virou assunto da novela das oito, 
entrou nas entrevistas populares dos telejornais (...) e finalmente aderiu à paisagem, como uma igreja, uma árvore" (ÂNGELO, 2006, p. 185).

As pessoas já se preparavam para passar pela Casa de Vidro, como quem vai ao planetário, à praça ou, em termos contemporâneos, como quem vai dar uma passada no shopping. A passividade popular atinge seu ápice no fantástico encerramento do conto, quando o último (Ruído) nos revela a derradeira conversa vigiada e transmitida, dentro desse recorte temporal:

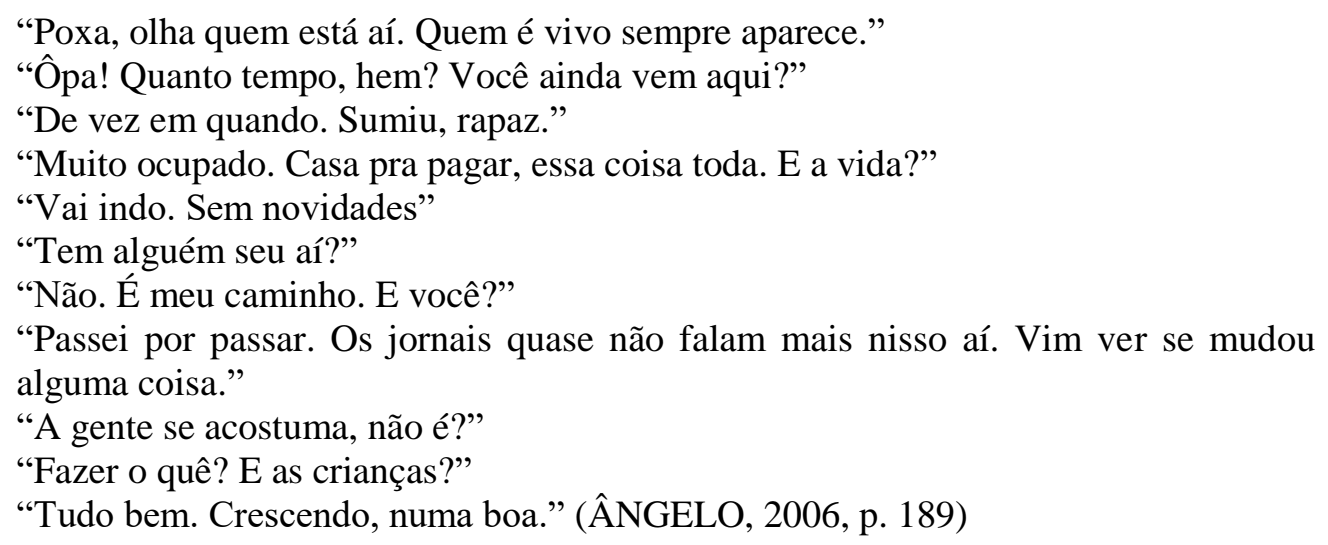

Nas expressões “Não. É meu caminho", "Passei por passar” e “A gente se acostuma, não é?", percebemos o grau de passividade da população. A Casa de Vidro se tornou parte da paisagem, elemento da rotina local; afinal, as poucas reações contrárias foram duramente coibidas, até que se tornaram inexistentes: será tudo isso uma "alucinação coletiva”? Se não, por que tentar interferir em algo que não vai mudar? As pessoas já cruzam o ambiente sem surpresa, isentos do desejo de modificar aquela realidade, apáticos e seguindo o curso de suas vidas como se o local fosse mais um ponto turístico.

Um último elemento a ser ressaltado é o herói (não herói) nas Distopias. Nutrimos duas certezas quanto aos personagens das narrativas distópicas: primeiro, os heróis/heroínas estão presentes; segunda, eles (as) carecem das virtudes e atributos tradicionais dos heróis. Para Kothe (1985, p. 16), o anti-herói não se encaixa em um padrão de valores subjacente à perspectiva narrativa.

Anti-heróis protagonizam narrativas distópicas e carecem das típicas características dos heróis virtuosos, puros e dotados de rígidos preceitos éticos e morais, que lutam pela justiça e preferem morrer a serem considerados corruptos em um universo onde precisam ser símbolos exemplares de 
justiça e bondade. De acordo com o E-Dicionário de termos literários, de Carlos Ceia ${ }^{3}$, o anti-herói se opõe ao herói em dupla acepção. Primeiro, como protagonista, “o anti-herói reveste-se de qualidades opostas ao cânone axiológico positivo: a beleza, a força física e espiritual, a destreza, dinamismo e capacidade de intervenção, a liderança social, as virtudes morais". Embora possamos pensar nos Chefes e na própria casa como elementos à frente da narrativa, no conto de Ângelo, identificamos a figura do anti-herói no Experimentador, que engendra o experimento social macabro, leva a proposta aos seus superiores e não apresenta remorsos diante do que está a fazer com o núcleo oprimido da sociedade.

Por fim, o conto de Ivan Ângelo representa, em todos os seus aspectos essenciais, o gênero distópico em território nacional, e a ele se seguem raros nomes, a saber: Ignácio de Loyola Brandão, com Não verás país nenhum (1981) e Roberta Spindler, com A torre acima do véu (2014). Inspirado pelos impulsionadores da Distopia oitocentista, como Shelley e Wells, Ângelo deixou um legado entre as primeiras publicações desse novo gênero no Brasil. Esperamos que este trabalho possa contribuir para novas investigações sobre o gênero distópico em território nacional e também como forma de análise da nossa sociedade, bem como das razões de alerta social e político que as Distopias nos permitem, quanto ao presente e futuro do mundo como o conhecemos.

\section{REFERÊNCIAS}

ARENDT, Hannah. As Origens do Totalitarismo: totalitarismo, o paroxismo do poder. Rio de Janeiro: Ed. Documentário, 1979.

ÂNGELO, Ivan. A Casa de Vidro. IN: FERNANDES, Rinaldo de (org). Contos Cruéis. São Paulo: Geração Editorial, 2006, p.161-189.

FIGUEIREDO, Carolina Dantas. "Da utopia à distopia: política e liberdade". v.1. n. 03. Eutomia: Revista Online de Literatura e Linguística. Recife, Julho/2009. Disponível em: http://www.repositorios.ufpe.br/revistas/index.php/EUTOMIA/issue/view/118/showToc. Acesso em 02 jun. 2016.

FOUCAULT, Michel. Vigiar e punir: nascimento da prisão. Tradução de Raquel Ramalhete. Petrópolis, Vozes, 1987.

KOTHE, Flávio René. O herói. São Paulo: Ática, 1985.

\footnotetext{
${ }^{3}$ CEIA, Carlos. Anti-herói. IN: E-dicionário de termos literários de Carlos Ceia. Disponível em: http://edtl.fcsh.unl.pt/business-directory/5952/anti-heroi/. Acesso em 20 jan. 2018
} 
TODOROV, Tzvetan. A narrativa fantástica. In: As estruturas narrativas. São Paulo: Perspectiva, 2013, p. 147-166.

TOMACHEVSKI, Boris. Temática. IN: TODOROV, Tzvetan. Teoria da Literatura: textos dos formalistas russos. São Paulo: Editora Unesp, 2013, p. 305-356.

Recebido em 04/08/2018

Aceito em 16/01/2019 